\title{
Enfrentamento da COVID-19 e as possibilidades para promover a saúde: diálogos com professores
}

Coping with COVID-19 and the possibilities to promote health: dialogues with teachers

Enfrentamiento del COVID-19 y las posibilidades para promover la salud: diálogos con profesores

\author{
Jeane Barros de Souza ${ }^{\mathrm{I}}$, Ivonete Teresinha Schülter Buss Heidemann ${ }^{\mathrm{II}}$, \\ Julia Valeria de Oliveira Vargas Bitencourt ${ }^{\mathrm{III}}$, Denise Consuelo Moser Aguiar ${ }^{\mathrm{IV}}$, \\ Carine Vendruscolov, Maria Sylvia de Souza Vitalle ${ }^{\mathrm{vI}}$
}

\begin{abstract}
Resumo: Objetivo: compreender a vivência de professores do ensino fundamental no enfrentamento da COVID19, desvelando as suas possibilidades para promover sua própria saúde nesse contexto pandêmico. Método: estudo qualitativo, tipo ação participante, com guia metodológico do Itinerário de Pesquisa de Paulo Freire, que integra três etapas: Investigação Temática; Codificação e Descodificação; Desvelamento Crítico. Participaram do Círculo de Cultura 14 professoras do ensino fundamental, atuantes em escolas particulares e públicas de diferentes estados brasileiros. Resultados: a análise resultou dois temas geradores: 1) Desafios no enfrentamento da COVID-19; 2) Possibilidades para promover saúde de professores em tempos de COVID-19. Conclusão: os desafios do ensino remoto para o enfrentamento da COVID-19 envolvem sobrecarga, estresse, ansiedade, medos, preocupações, insegurança e saudade da escola. Como possibilidades para promover a saúde, as professoras buscam apoio familiar, organizando tempo para cuidar de si e aliviar a ansiedade por meio de leitura de livros, filmes e prática de exercícios.
\end{abstract}

Descritores: Saúde do Trabalhador; Infecções por Coronavírus; Pandemia; Adaptação Psicológica; Promoção da Saúde

Abstract: Objective: to understand the experience of elementary school teachers in coping with COVID-19, unveiling the possibilities to promote their health in this pandemic context. Method: qualitative study, participant action type, with a methodological guide of Paulo Freire's Research Itinerary, which includes three stages:

\footnotetext{
${ }^{I}$ Enfermeira. Doutora em Ciências, Pós-doutorado em Enfermagem, Docente do Curso de Enfermagem da Universidade Federal da Fronteira Sul - UFFS, Campus Chapecó. Chapecó, Santa Catarina, Brasil. E-mail: jeanebarros18@gmail.com; Orcid: https://orcid.org/0000-0002-0512-9765 II Enfermeira. Ph.D. Professora Associada do Departamento de Enfermagem da Universidade Federal de Santa Catarina - UFSC. Florianópolis, Santa Catarina, Brasil. E-mail: ivoneteheidemann@ufsc.br; Orcid: https://orcid.org/0000-0001-6216-1633

III Enfermeira, Doutorado; Docente do Magistério Superior; Universidade Federal da Fronteira Sul - UFFS; Campus Chapecó. Porto Alegre, RS, Brasil. E-mail: julia.bitencourt@uffs.edu.br; Orcid:https://orcid.org/0000-0002-3806-2288

IV Enfermeira. Doutora em Educação, em Estágio Pós doutoral, Professora Adjunta do Magistério Superior; Curso de Enfermagem, Universidade da Fronteira Sul - UFFS, Campus Chapecó. Chapecó, Santa Catarina, Brasil. E-mail: denise.moser@uffs.edu.br; Orcid: https://orcid.org/0000-0002-8708-6518

V Enfermeira, Pós-doutorado em Enfermagem; Professora da Graduação e Pós-graduação em Enfermagem da Universidade do Estado de Santa Catarina - UDESC. Chapecó, SC, Brasil. E-mail: carine.vendruscolo@usesc.br; Orcid: https://orcid.org/0000-0002-5163-4789

VI Professora Adjunta; Doutora do Setor de Medicina do Adolescente, Professora Permanente do Programa de Pós-Graduação Educação e Saúde na Infância e Adolescência, Universidade Federal de São Paulo - Unifesp. São Paulo, SP, Brasil. E-mail: sylviavitalle@gmail.com Orcid: https://orcid.org/0000-0001-9405-4250
} 
Thematic Research; Encoding and Decoding; Critical Unveiling. Fourteen elementary school teachers, active in private and public schools in different Brazilian states, participated in the Culture Circle. Results: the analysis resulted in two generating themes: 1) Challenges in coping with COVID-19; 2) Possibilities to promote teacher's health in times of COVID-19. Conclusion: the challenges of remote education to cope with COVID-19 involve overload, stress, anxiety, fears, concerns, insecurity, and missing school. As the possibilities to promote health, teachers seek family support, organizing time to take care of themselves and alleviate anxiety through reading books, watching movies, and exercising.

Descriptors: Occupational Health; Coronavirus Infections; Pandemics; Adaptation, Psychological; Health Promotion

Resumo: Objetivo: compreender a vivência de professores do ensino fundamental no enfrentamento da COVID19, desvelando as suas possibilidades para promover sua própria saúde nesse contexto pandêmico. Método: estudo qualitativo, tipo ação participante, com guia metodológico do Itinerário de Pesquisa de Paulo Freire, que integra três etapas: Investigação Temática; Codificação e Descodificação; Desvelamento Crítico. Participaram do Círculo de Cultura 14 professoras do ensino fundamental, atuantes em escolas particulares e públicas de diferentes estados brasileiros. Resultados: a análise resultou dois temas geradores: 1) Desafios no enfrentamento da COVID-19; 2) Possibilidades para promover saúde de professores em tempos de COVID-19. Conclusão: os desafios do ensino remoto para o enfrentamento da COVID-19 envolvem sobrecarga, estresse, ansiedade, medos, preocupações, insegurança e saudade da escola. Como possibilidades para promover a saúde, as professoras buscam apoio familiar, organizando tempo para cuidar de si e aliviar a ansiedade por meio de leitura de livros, filmes e prática de exercícios.

Descritores: Saúde do Trabalhador; Infecções por Coronavírus; Pandemia; Adaptação Psicológica; Promoção da Saúde

\section{Introdução}

Em dezembro de 2019, a Organização Mundial da Saúde (OMS) foi alertada sobre vários casos de pneumonia na cidade de Wuhan, província de Hubei, na China. As autoridades chinesas confirmaram que haviam identificado um novo tipo de coronavírus, que foi denominado de Síndrome Respiratória Aguda Grave Coronavírus 2 (SARS-CoV-2), sendo o responsável pela doença Coronavirus Disease 2019, reconhecida pela abreviatura COVID-19. ${ }^{1-2}$ Desde a sua identificação, a escala epidêmica da doença aumentou rapidamente, com casos em outras regiões e países. ${ }^{3}$ Em março de 2020, a OMS declarou a situação como pandêmica, aconselhando os países do mundo a agir por meio de medidas de prevenção e controle de sua disseminação, indicando o que representa um dos maiores desafios sanitários em escala mundial deste século. ${ }^{1-2}$ 
3 | Souza JB, Heidemann ITSB, BitencourtIII JVOV, Aguiar DCM, Vendruscolo C, Vitalle MSS

Tal conjuntura impõe desafios à vigilância epidemiológica e aos programas de políticas públicas, considerando medidas que reduzam as desigualdades de acesso aos sistemas de saúde e às condições estruturais para o autocuidado. Nesse sentido, estar atento ao comportamento dessa pandemia nas diferentes regiões é fundamental para a atualização das estratégias de enfrentamento dessa emergência global e suas repercussões no nível local. ${ }^{4}$

No Brasil, medidas já foram tomadas em prol da redução do contato físico entre as pessoas, como a ausência de aulas presenciais nas escolas, a reorganização do ensino a partir de um trabalho remoto, bem como a revisão das condutas cotidianas com o reforço do uso de medidas de higiene, intensificação da lavagem de mãos, uso de álcool e máscara em todos os espaços. Todavia, essas medidas de proteção precisam vir acompanhadas de orientações sobre como agir no contexto de trabalho dos profissionais da educação, uma vez que este evolui velozmente e cria novas situações de risco a serem adequadamente manejadas. ${ }^{5}$

Medidas de prevenção e controle de infecções são essenciais para evitar a disseminação da doença nos locais de trabalho. Destaque é dado aos programas de treinamento da equipe. O plano estratégico lista indicadores cujo desempenho deve ser monitorado como parte de avaliação do plano de resposta e prontidão estratégica de cada setor. ${ }^{4-6}$

Segundo a OMS, a principal finalidade dos Serviços de Saúde Ocupacional consiste na promoção de condições laborais que garantam elevado grau de qualidade de vida no trabalho, protejam a saúde dos trabalhadores, promovam o bem-estar físico, mental e social, prevenindo e controlando os acidentes e as doenças por meio da redução das condições de risco. O referido serviço não se limita a cuidar das condições físicas do trabalhador, já que trata da questão psicológica, sendo que para os empregadores supõe um apoio ao aperfeiçoamento do funcionário e à conservação da sua capacidade de trabalho. ${ }^{7}$

O sistema de ensino brasileiro estagnou de maneira presencial, mas algumas instituições se organizaram para desenvolver ensino remoto com a finalidade de dar continuidade ao ano 
Enfrentamento da COVID-19 e as possibilidades para promover a saúde: diálogos... $\mid 4$

letivo. Nesse âmbito, os professores precisaram reinventar sua maneira de ensinar com aulas mediadas por ambiente virtual, atividades on-line e demais ações virtuais. No entanto, relatório do United Nations International Children's Emergency Fund (UNICEF) alerta que pelo menos um terço das crianças em idade escolar do mundo não consegue acessar o ensino a distância durante o fechamento das escolas no período pandêmico imposto pela COVID-19. Tal relatório aponta ser urgente investimentos para eliminar a exclusão digital, com vistas a abarcar todas as crianças com aprendizagem remota, priorizando a reabertura segura das escolas. ${ }^{8}$

Outro ponto a ser considerado é o fato de que o exercício das atividades laborais e as condições de trabalho se apresentam como fontes potenciais de exposição ao vírus e território de disseminação da doença, fator de estresse para os professores. Nesse cenário, para assegurar condições laborais que propiciem redução na transmissão do vírus, medidas organizacionais necessitam ser discutidas no âmbito de cada atividade de trabalho. Cabe destacar que a práxis da saúde do trabalhador há de ser considerada no rol das medidas e ações de saúde pública, voltadas ao controle da pandemia. A saúde ocupacional dos trabalhadores da educação necessita de planejamento e tomada de decisões por autoridades responsáveis, com base em informações científicas, com transparência e integração de ações, a fim de garantir as dimensões do trabalho, fator estruturante da sociedade. ${ }^{6}$

A saúde ocupacional não se limita apenas a cuidar das condições físicas do trabalhador, já que também trata da questão psicológica e supõe um apoio à conservação da sua capacidade de trabalho. Segundo a OMS, é necessário proteger a saúde dos trabalhadores, promovendo o bem-estar físico, mental e social, prevenindo e controlando as doenças por meio da redução das condições de risco. ${ }^{7}$

O contexto educacional de enfrentamento da COVID-19 suscita dúvidas e gera sentimento de impotência, que a um só tempo tem conduzido os professores a rever conceitos, reconfigurar ações e gestos, vivenciando os espaços virtuais como algo atual e presente nas relações de trabalho e convívio pessoal. Assim, emergiu a seguinte questão de pesquisa: como é 
5 | Souza JB, Heidemann ITSB, BitencourtIII JVOV, Aguiar DCM, Vendruscolo C, Vitalle MSS

a vivência de professores do ensino fundamental no enfrentamento da COVID-19 e quais suas possibilidades para promover saúde nesse contexto pandêmico?

Há escassas reflexões sobre o enfrentamento da COVID-19 e as suas repercussões para a saúde dos professores do ensino fundamental no Brasil, sendo premente a necessidade de promover o bem-estar desses profissionais. Logo, este estudo teve como objetivo compreender a vivência de professores do ensino fundamental no enfrentamento da COVID-19, desvelando as suas possibilidades para promover sua própria saúde no contexto pandêmico.

\section{Método}

Trata-se de um estudo qualitativo, do tipo ação participante, ${ }^{9}$ no qual os dados são contextualizados a partir da realidade dos participantes. Fundamentou-se nos pressupostos teóricometodológicos de Paulo Freire, ${ }^{10}$ que se consolida por uma concepção pedagógica libertadora, dialógica e horizontalizada. Percorreu-se o Itinerário de Pesquisa, que possui três etapas interligadas entre si, a saber: Investigação Temática; Codificação e Descodificação; e o Desvelamento. ${ }^{11-12}$

As etapas do Itinerário de Pesquisa ocorrem em espaços denominados de Círculos de Cultura, em que pessoas se encontram, permitindo a vivência de uma experiência dialógica, com reflexões sobre situações da realidade de interesse coletivo comum. Esse arcabouço pode constituir-se em estratégia para práticas de promoção da saúde, ${ }^{12}$ coadunando, assim, com a proposta deste estudo. Diante da pandemia, com a necessidade de restrição social, somada ao fato de que os participantes residiam em diferentes localidades, o Círculo de Cultura foi realizado de maneira virtual, sendo utilizado um aplicativo gratuito, por meio da câmera de dispositivos eletrônicos, o que se mostrou inovador e caminhou ao encontro das necessidades dos professores, que dispunham de tempo limitado nas agendas de trabalho on-line.

Participaram do estudo 14 professoras do ensino fundamental, residentes em diferentes localidades do Brasil. A opção pelo número de participantes se deu considerando o tipo de 
Enfrentamento da COVID-19 e as possibilidades para promover a saúde: diálogos... | 6

abordagem, visto que o Itinerário de Pesquisa de Paulo Freire prevê que os Círculos de Cultura possam ser realizados com um número reduzido e irregular de participantes, a fim de oportunizar aproximação entre pesquisadores e sujeitos da pesquisa pela práxis dialógica. ${ }^{11}$ Para realizar o contato com as participantes, primeiramente seis professoras do convívio social das pesquisadoras foram convidadas, via telefone, para ingressar no estudo. Posteriormente, por meio do método de amostragem Snowball, ${ }^{13}$ essas docentes convidaram outras colegas de profissão para também integrar o Círculo de Cultura Virtual. Todas que foram convidadas aceitaram participar da pesquisa, não havendo recusas.

Como critérios de inclusão foram consideradas as professoras com no mínimo dois anos de atuação no ensino fundamental do setor púbico e/ou privado. Considerou-se critério de exclusão os docentes em licença no período do estudo, bem como não possuir acesso à internet e dispositivos eletrônicos para participar do Círculo de Cultura Virtual. No dia anterior à realização do Círculo, as professoras receberam orientações sobre a utilização do aplicativo, com agendamento da data e horário, por meio de mensagem via WhatsApp, sendo também solicitado que providenciassem folha de papel A4 e canetões.

O Círculo de Cultura Virtual foi realizado no dia 15 de junho de 2020, com duração de aproximadamente duas horas e desenvolveu-se sob mediação de uma enfermeira, doutora, com experiência na condução desse tipo de abordagem metodológica. Todas as professoras se apresentaram, expondo seu nome e sua experiência na área educacional; em seguida, a mediadora compartilhou a proposta, detalhando a metodologia de trabalho e apresentou em suas mãos um girassol em um vaso decorativo, sendo que de maneira simbólica o ofereceu para todas as participantes do Círculo.

O diálogo inicial contemplou o levantamento dos temas geradores, desencadeado por questões guias disparadoras acerca da temática do enfrentamento da COVID-19 e as possibilidades para promover a saúde dos professores do ensino fundamental. Por meio da 
Investigação Temática, buscou-se a identificação dos temas geradores, a partir das falas mais significativas e problematizadas pelos participantes, mediados pelo pesquisador no Círculo de Cultura Virtual. O diálogo oriundo da realidade das participantes e com base nas experiências cotidianas do novo cenário educacional encaminhou-se para o debate das situações concretas e reais que os professores estavam vivenciando no seu aqui e agora, configurando-se os temas a serem investigados. Esse exercício, essencialmente, conduziu à análise crítica da realidade em busca de soluções adequadas que faz principiar o processo educativo libertador. ${ }^{11}$

Para percorrer as etapas do Itinerário Freiriano de maneira concreta, criativa e lúdica, optou-se por realizar uma analogia com o desenvolvimento do girassol, que depende de todas as suas fases para crescer de maneira saudável e poder florir, tal qual as etapas do Itinerário de Pesquisa de Paulo Freire, conforme ilustra a Figura 1.

Figura 1 - Itinerário Freiriano: analogia com o desenvolvimento do girassol. Chapecó, SC, 2020.

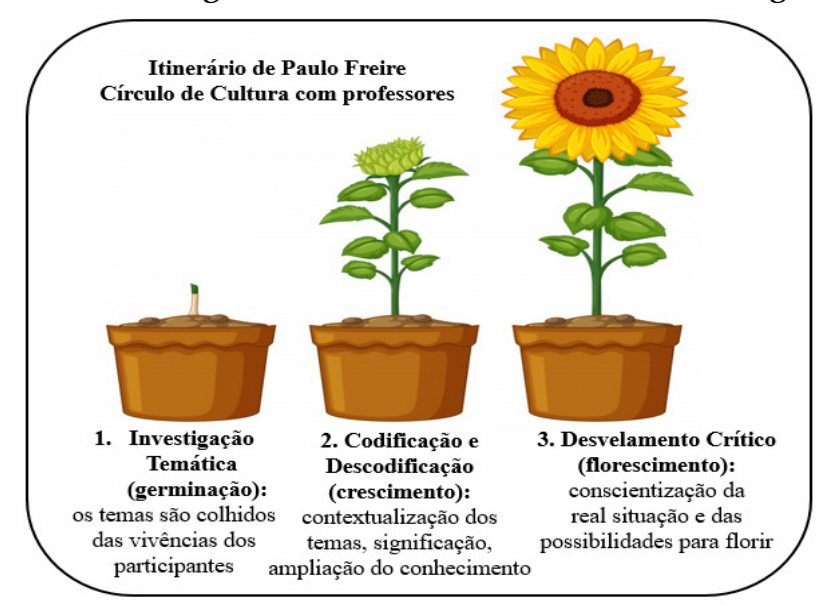

Fonte: adaptado pelas autoras a partir de: https://br.freepik.com/vetores-gratis/tres-vasos-de-plantas-degirassol_1339362.htm.

Assim, a etapa da Investigação Temática foi comparada à germinação do girassol, que é uma fase em que as sementes são lançadas em uma terra fértil a fim de que nada impeça o desabrochar do broto, que precisará crescer de maneira forte e saudável. A mediadora abordou que a sociedade atual está enfrentando diversos desafios no enfrentamento da pandemia, impedindo o "desabrochar do broto", representado pela vida saudável. A partir de então, para 
Enfrentamento da COVID-19 e as possibilidades para promover a saúde: diálogos... $\mid 8$

incentivar o diálogo no Círculo de Cultura, lançou o seguinte questionamento: o que tem impedido você de viver de maneira mais saudável o enfrentamento da COVID-19?

As professoras compartilharam os desafios encontrados na vivência da pandemia e tiveram a oportunidade de ouvir umas às outras, mediante o diálogo e a reflexão sobre a realidade vivida nas ações cotidianas de cada uma, principalmente no mundo do seu trabalho, abrindo possibilidades para a sua transformação. Nesse momento, definiram dois temas geradores para discussão: 1) Desafios no enfrentamento da COVID-19; 2) Possibilidades para promover saúde em tempos da COVID-19.

A partir dos temas geradores, a etapa da Codificação é relevante, pois organiza as ideias expressas previamente, de maneira aleatória, fazendo com que os temas recebam significação na medida em que se substitui a visão mágica por uma visão crítica e social do assunto discutido. Esse movimento, oriundo da Codificação, possibilita o olhar para a situação destacada, o fato em si, organizado por meio da elaboração dos códigos imbricados aos temas geradores, o que conduz a análise da situação vivida e engendra a Descodificação. Dessa forma, a dinâmica é codificar para após descodificar, pois esse movimento possibilita que os participantes perpassem pela dialética, ao admirar e refletir sobre sua ação, perscrutando as contradições inerentes. Essa nova leitura da realidade objetiva ampliar e exaltar o poder reflexivo, o que promove a sensação de se ser capaz de transformar o mundo e superar limites. ${ }^{11}$

$\mathrm{Na}$ etapa da Codificação e da Descodificação, a mediadora voltou os olhos ao girassol no vaso, apontando que ele já tinha sido um pequenino broto, que venceu os desafios dos dias intensamente ensolarados e chuvosos, continuando a crescer até o seu completo desenvolvimento; em seguida, apresentou às participantes uma cartolina, contendo o desenho de um girassol em ambos os lados, e anotou o primeiro tema gerador no centro do girassol, de um lado. O mesmo fez com o segundo tema gerador, na outra parte da cartolina. 
9 | Souza JB, Heidemann ITSB, BitencourtIII JVOV, Aguiar DCM, Vendruscolo C, Vitalle MSS

Para tanto, as professoras foram convidadas para responder na sua folha de papel A4 à seguinte pergunta: quais as maiores dificuldades na vivência da pandemia no cotidiano do trabalho, que impedem um viver de maneira mais saudável? Do outro lado da sua folha, as participantes responderam ao seguinte questionamento: quais as possibilidades para promover a saúde diante da COVID-19? Enquanto as docentes foram respondendo às questões, a mediadora cantou a música “Girassol”, da autoria de Whindersson Nunes, despertando emoções.

As participantes foram apresentando seus desafios e sugestões para promover a saúde na vivência da COVID-19. Enquanto as professoras dialogavam, a mediadora escreveu nas pétalas das flores do girassol, desenhado na cartolina, um termo ou frase que representasse as percepções compartilhadas por elas.

O foco na realidade, intrínseco ao Itinerário Freiriano, e a ampliação do escopo de visão acerca de um tema permitem aos participantes alcançarem a etapa do Desvelamento Crítico. Nesse momento, espelham-se as reflexões preliminares das propostas extraídas da Codificação, que é objetiva, com princípios da subjetividade interpretativa. Logo, os temas são reduzidos e cisões são estruturadas visando melhor conhecê-los a partir de uma totalidade. Assim, estabelece-se a tomada de consciência da situação existencial, em que se descobrem os limites e as possibilidades diante da realidade. Descortina-se, então, o processo de ação-reflexão-ação, que capacita as pessoas a compreender e evidencia-se a importância de uma ação concreta, cultural, política e social, aspirando-se situações-limite e o enfrentamento das contradições. Consequentemente, desvela-se a realidade como um processo arquitetado em conjunto, no qual o diálogo compõe o elemento dinamizador da ação e da reflexão. ${ }^{11}$

Para a etapa do Desvelamento Crítico, a mediadora abordou que quando o girassol floresce, o seu caule posiciona a flor na direção do Sol. Mas, quando não há Sol, essa flor se vira para outro girassol, em busca de luz. Da mesma maneira, a mediadora comentou que nesses tempos mais escuros, no enfrentamento da COVID-19, cabe o desafio de cada uma ampliar sua 
Enfrentamento da COVID-19 e as possibilidades para promover a saúde: diálogos... | 10

luz, buscando promover seu autocuidado em prol de uma vida mais saudável. Contudo, quando faltar forças, poderão voltar-se para outras pessoas e trocar experiências e apoio, como o momento proporcionado pelo Círculo de Cultura Virtual, em que uma pode ouvir a outra e aprender mutuamente, em busca do viver saudável.

Para tanto, a mediadora convidou as docentes para desvelar os aprendizados significativos no enfrentamento da COVID-19 e sobre a participação no Círculo de Cultura Virtual. As professoras compartilharam seus significados na vivência do Círculo de Cultura, que foi encerrado com todas cantando juntas, mesmo distantes geograficamente, a música "É preciso saber viver”, composição de Roberto Carlos.

Os diálogos do Círculo de Cultura Virtual foram gravados, transcritos e organizados em duas pastas digitais, de acordo com os dois temas geradores escolhidos pelas professoras para discussão. Cabe salientar que o processo de Desvelamento Crítico para análise dos dados (temas) ocorreu concomitantemente com a Investigação Temática, de acordo com o Itinerário de Pesquisa de Paulo Freire, que prevê o processo analítico, que acontece de maneira contínua e com a participação de todos os envolvidos no Círculo de Cultura.

Os participantes analisaram os temas (dados) codificados e descodificados como sendo os mais importantes que deveriam ser desvelados no Círculo de Cultura Virtual e tiveram um novo olhar sobre a realidade vívida. Para análise dos dados, realizaram-se a leitura e a releitura das duas pastas digitais, que continham os registros dos diálogos referentes aos dois temas geradores discutidos no Círculo, articulando com a temática do enfrentamento da COVID-19 e as possibilidades de promover saúde, o que possibilitou a ressignificação dos temas e o Desvelamento Crítico, de acordo com a abordagem de Paulo Freire. ${ }^{11-12}$

O estudo seguiu conforme os preceitos éticos da Resolução 466, de dezembro de 2012, do Conselho Nacional de Saúde. O Termo de Consentimento Livre e Esclarecido foi encaminhado via e-mail para as participantes, que o assinaram e o devolveram às pesquisadoras. Para 
11 | Souza JB, Heidemann ITSB, BitencourtIII JVOV, Aguiar DCM, Vendruscolo C, Vitalle MSS

preservar o anonimato, nomearam-se as professoras com nome de flores. A pesquisa foi aprovada pelo Comitê de Ética de uma universidade do Sul do Brasil, com parecer número 4.068.387, em 03 de junho de 2020.

\section{Resultados}

As 14 professoras do ensino fundamental eram do sexo feminino, com idade entre 32 e 48 anos, sendo que três atuavam em escolas públicas e 11 em escolas privadas, todas com mais de oito anos de experiência na área educacional. As participantes residiam no Brasil, em diferentes estados, sendo sete de Santa Catarina, três de São Paulo, duas do Rio de Janeiro e duas do Rio Grande do Sul.

Ao dialogar sobre o primeiro tema gerador, Desafios no enfrentamento da COVID-19, as professoras puderam ampliar os seus significados na vivência das repercussões da pandemia em suas vidas e em seu trabalho, em que perceberam que outras professoras também estavam enfrentando situações semelhantes. As participantes referiram o sentimento de medo de perder o emprego e abordaram também medo de seus familiares adquirirem a COVID-19:

Foi muito bom foi esse tempo aqui com vocês para perceber que outros professores do Brasil estão enfrentando situações como as que eu enfrento. (Margarida)

Eu tenho muito medo de perder o meu emprego com toda essa situação que nos envolve. (Rosa)

Eu tenho medo de minha família, dos meus pais pegarem essa doença terrível. (Girassol)

As participantes do estudo apontaram que a situação de pandemia gerou a necessidade de trabalhar de maneira remota, dentro de suas próprias casas, o que repercutiu em intenso labor, estresse, ansiedade e insegurança. Foi preciso reaprender a ensinar diante das dificuldades de 
Enfrentamento da COVID-19 e as possibilidades para promover a saúde: diálogos... $\mid 12$

adaptação às novas tecnologias, com treinamento insuficiente, concomitante ao cotidiano de ser mãe, esposa, dona de casa e professora ao mesmo tempo:

Essa pandemia fez com que a gente tivesse que trabalhar dentro de casa e de maneira remota. (Amor-Perfeito)

Nunca trabalharei tanto como nessa pandemia. (Azaleia)

Isso tudo já está me dando estresse e me sinto muito ansiosa. (Antúrio)

Estamos tendo que reaprender a ensinar porque eu nunca fiz isso. Jamais imaginei que um dia eu ia ensinar as crianças de maneira virtual. (Begônia)

Eu não sei nada dessas tecnologias, então tem sido um estresse esse ensino remoto, tendo que se adaptar e reaprender todos os dias. Isso traz insegurança porque não tivemos treinamento adequado. (Rosa)

É um desafio ensinar de maneira remota dentro de casa e ao mesmo tempo ser mãe, esposa, dona de casa. Isso não é fácil! (Violeta)

No Círculo de Cultura Virtual, ainda desvelaram o sentimento de saudade das aulas presenciais na escola e dos diálogos com os estudantes. Elas revelaram sentir tristeza de visualizar a escola vazia, sem vida com a ausência das crianças. E ainda afirmaram sentir preocupação com o futuro, diante das incertezas que a pandemia repercutiu:

Eu tenho muita saudade das aulas presenciais. (Camélia)

A escola sem as crianças fica vazia, sem vida. Tenho saudade dos diálogos com as crianças na escola. (Calêndula)

Tudo está muito incerto com a pandemia e isso nos faz ter preocupação com o futuro. (Cravo)

Após o partilhar dos desafios no enfrentamento do momento pandêmico, as professoras refletiram que seria necessário superar as dificuldades e discutiram sobre o segundo tema 
13 | Souza JB, Heidemann ITSB, BitencourtIII JVOV, Aguiar DCM, Vendruscolo C, Vitalle MSS

gerador, considerando a possibilidade de promover a saúde em tempos de COVID-19, empoderando-se mutuamente.

As docentes abordaram ser necessário ter humildade e solicitar ajuda nos momentos de dificuldade de adaptação com as ferramentas virtuais. Além disso, afirmaram que buscam apoio dos familiares para auxiliar no cuidado com os filhos para ministrar as aulas remotas:

É preciso ser humilde e reconhecer que preciso de ajuda. Eu peço ajuda porque sei que tenho dificuldades com essas ferramentas tecnológicas no ensino e tudo isso é novidade para a gente. (Camélia)

Para conseguir dar aula em casa, eu conto com o importante apoio da minha família, para poder cuidar dos meus filhos enquanto eu dou aula. Tive que pedir ajudar! (Rosa)

No Círculo de Cultura, também dialogaram a respeito de ter esperança e buscar se renovar a cada manhã, crendo em dias melhores, com dedicação de um tempo para cuidar de si. Ainda, discutiram que para promover sua saúde assistem a filmes para distrair a mente e aliviar a ansiedade, bem como praticam exercícios físicos e fazem leituras, vivendo um dia de cada vez:

Eu sempre durmo com a esperança de que amanhecerei mais renovada a cada manhã. (Lírio)

A gente precisa também crer em dias melhores, que tudo isso logo vai passar. (Rosa)

É preciso tirar um tempo para cuidar de si. (Antúrio)

Eu assisto filmes com o meu marido para distrair um pouco a minha mente. (Hortênsia)

Tenho buscado aliviar a minha ansiedade lendo livro, assistindo filmes e fazendo exercícios físicos. (Gérbera)

É preciso viver um dia de cada vez e aliviar toda essa nossa ansiedade. (Cravo) 
Enfrentamento da COVID-19 e as possibilidades para promover a saúde: diálogos... | 14

As professoras compartilharam que buscam colher aprendizado dos desafios que emergiram na vivência da pandemia da COVID-19, voltando-se mais para Deus:

De fato, temos enfrentado vários desafios, só que eu tento obter aprendizado na vivência dessa pandemia. (Amor-Perfeito)

Tenho buscado me aproximar mais de Deus. (Calêndula)

As docentes refletiram sobre a importância da participação no Círculo de Cultura Virtual, destacando-o como uma oportunidade para promover saúde mental e aprendizado, mediante a troca de experiências e de esperanças em um momento marcante em suas vidas. Elas se sentiram acolhidas e revigoradas para dar continuidade às aulas on-line, como se evidencia na Figura 2.

Figura 2 - Significados das professoras na vivência do Círculo de Cultura Virtual. Chapecó, SC, 2020.

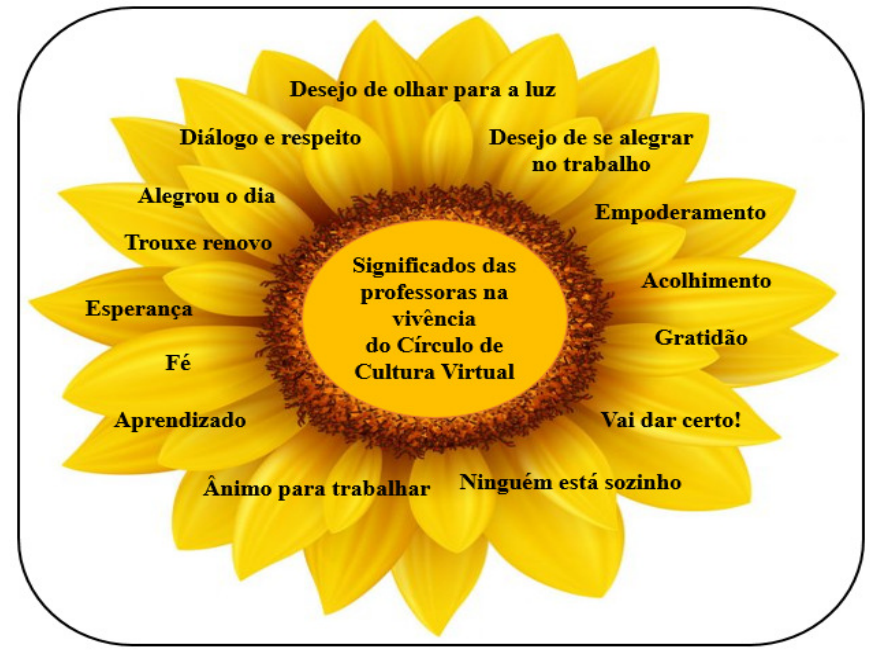

Fonte: adaptado pelas autoras a partir de https://br.depositphotos.com/vector-images/girassol.html

\section{Discussão}

A docência é permeada pela ação mediadora de ensinar e aprender. Nesse movimento, situações que inviabilizem essa ação exigem que os professores repensem a atuação no sentido de (re)conduzir os processos educacionais, como ocorreu no enfrentamento da COVID-19. 
15 | Souza JB, Heidemann ITSB, BitencourtIII JVOV, Aguiar DCM, Vendruscolo C, Vitalle MSS

$\mathrm{Na}$ discussão do primeiro tema gerador, em que as professoras abordaram acerca dos desafios no enfrentamento da COVID-19, ficou evidente a dificuldade no manuseio das novas tecnologias. Considerando que, além de lidar com estas, há o fato de que o fazem a partir das suas casas, envolvidas por um novo contexto, com filhos e afazeres domésticos, motivo de ansiedade, insegurança e estresse diante do momento vivido. As angústias nesse período, vivenciado por toda a sociedade, imprimem um sentimento de impotência e medo, que vai além da doença, dos sintomas e da morte, pois a economia foi afetada profundamente e, nesse sentido, os educadores temem as demissões em massa, já que a situação econômica abrangeu também esse setor.

De modo geral, os professores enfrentam em seu cotidiano uma vasta lista de atividades a executar. Porém, com a pandemia da COVID-19, agravou-se demasiadamente, interferindo na saúde mental desses profissionais. Devido à atual conjuntura e à retomada das atividades educacionais de maneira remota no ensino fundamental, tornou-se necessária a organização de uma nova metodologia de ensino, o que repercutiu na imediata adaptação às estratégias tecnológicas, com vistas a ofertar uma educação a distância de qualidade. ${ }^{14}$

A estratégia de retomada das aulas de maneira remota, sem um treinamento adequado e planejamento conveniente para ofertar a continuidade pedagógica aos estudantes, pode ocasionar a sobrecarga de informações, dificuldades na adaptação e na capacitação dos professores. Esses novos desafios impostos tendem a desencadear mal-estar físico e mental, surgindo sintomas como estresse, fadiga, ansiedade e depressão, o que repercute em prejuízos à saúde desses profissionais. ${ }^{14} \mathrm{O}$ fato é que muitos professores precisaram adaptar os conteúdos e as suas aulas para o formato remoto, sem dominar essas ferramentas e tecnologias, sendo que a falta ou escassez de experiência nessa modalidade suscita insegurança aos novos meios de ensino, ${ }^{15}$ corroborando os achados desta pesquisa. 
Enfrentamento da COVID-19 e as possibilidades para promover a saúde: diálogos... | 16

Em pesquisa realizada sobre o sentimento e a percepção dos educadores brasileiros da rede básica perante o contexto educacional em decorrência da COVID-19, obteve-se a avaliação do impacto do momento atual na saúde mental dos professores, em uma escala likert pontuada de 1 até 5 , em que a média ficou em 2,16. A pesquisa mostrou que mais de $70 \%$ dos professores estão buscando apoio na seguinte ordem de prioridade: informacional, emocional e financeiro. ${ }^{16}$

O sofrimento de professores e seu consequente adoecimento têm sido objeto de estudo, dada as condições sociais e econômicas que permeiam o cenário do seu trabalho. Embora se evidencie na literatura o comprometimento da saúde mental de professores ao longo dos anos, escassas pesquisas relatam sobre a gestão da saúde pública em relação a essa população específica. ${ }^{14}$ Para tal achado, ponderou-se sobre três possíveis explicações: 1) Os programas voltados para essa categoria estão sendo realizados, contudo os gestores não estão divulgando as experiências, consequentemente não existem publicações; 2) As instituições de pesquisa não têm se interessado pelo tema; 3) Não existem programas que trabalhem com adoecimento dos professores no âmbito das políticas públicas. ${ }^{17}$

Sabe-se que situações que despertam nos trabalhadores sensações de sofrimento, insegurança, preocupações e angústia, aliadas à necessidade de responder à mobilização emocional resultante, deixam eles em situações que exigem estratégias e manejos psicológicos a fim de conviver e lidar com sua rotina de trabalho. ${ }^{18}$ Somado a isso, com a necessidade de distanciamento social, perdeu-se a presença dos estudantes na escola, que de maneira inesperada tornou-se vazia e silenciosa, despertando nos professores o sentimento de saudade da instituição escolar no desenvolvimento do seu papel educacional e também do diálogo com os estudantes. Destaca-se que o estreitamento de vínculos fortalece o conhecimento dialógico e plural no processo ensinoaprendizagem, resultando em educadores e educandos envolvidos na construção conjunta de saberes, o que se configura como fator que humaniza e transforma a realidade. ${ }^{19}$ 
17 | Souza JB, Heidemann ITSB, BitencourtIII JVOV, Aguiar DCM, Vendruscolo C, Vitalle MSS

Tem-se ciência dos grandes desafios que professores, estudantes e governantes vivenciam no momento pandêmico, bem como as implicações na saúde ocupacional desses profissionais da educação. Todavia, percebe-se que essa crise apenas exacerba um problema que já vinha sendo pontuado. Nesse sentido, urge a estruturação de políticas públicas que atinjam a questão fulcral da saúde dos professores, tanto quanto possibilitem a demonstração das evidências concretas, exibindo resultados das ações, promissores ou não, visando ao continuum ajustamento da grave situação.

Em virtude do contexto atual de pandemia, o Centro de Inovação para a Educação Brasileira (CIEB) construiu estratégias de aprendizagem remota para Secretarias de Educação, que foram organizadas com base em cinco planos diferentes para que os gestores públicos tomassem como referência e desenvolvessem seus próprios modelos de aula, quais sejam: transmissão de aulas e conteúdos educacionais via televisão; videoaulas gravadas e disponibilizadas em redes sociais; aulas remotas por redes sociais; envio de conteúdos digitais em ferramentas virtuais; disponibilização de plataformas de ensino on-line. Os planos advindos das estratégias foram lançados com base em estudos cujo foco foi o planejamento das Secretarias de Educação do Brasil para ensino remoto, liderado pelo CIEB em parceria com o Conselho Nacional de Secretários de Educação (CONSED), a União Nacional dos Dirigentes Municipais de Educação (UNDIME) e a Fundação Lemann. ${ }^{20}$

Percebe-se que iniciativas e projetos são colocados em prática, disponibilizando uma série de opções a professores e estudantes, no que tange aos recursos necessários à implementação efetiva das aulas remotas. Entretanto, embora a iniciativa seja assertiva, problematiza-se que o acesso a todo o aparato de opções providenciado ainda não atingiu sua abrangência plena, o que vai sustentando o desconforto dos professores. É importante ter claro que as tecnologias estruturadas em um nível macro, para atingirem seu efeito de maneira consistente, carecem de um processo de gestão de acesso que envolve comunicação e toda uma rede de profissionais que, no caminho entre a decisão política e a sala de aula, mesmo que de 
Enfrentamento da COVID-19 e as possibilidades para promover a saúde: diálogos... | 18

maneira remota, representada pelo professor, terão o papel de difundir, socializar e instrumentalizar-se para o uso dos recursos.

Reitera-se que o alcance desses recursos tem o potencial de aproximar, novamente, estudantes e professores em um processo de interação essencial na construção da educação, de modo que estudantes se sintam protagonistas em seu processo formativo e professores comprometidos com o seu papel de formador, tranquilizando e asserenando angústias sobrevindas de um momento absolutamente inusitado.

Durante o Círculo de Cultura Virtual, em face das repercussões positivas, fortalecimento e valorização pessoal e profissional, as professoras ampliaram o foco de visão acerca da situação atual de ensino cuja demanda implica o reinventar das práticas pedagógicas, considerando a substituição do espaço presencial para o virtual, mesmo que temporariamente. Nesse cenário, discutiram acerca do segundo tema gerador, envolvendo as reais possibilidades para promover sua saúde e se adaptar ao ensino-aprendizagem remoto, apesar dos desafios vultosos.

A saúde dos professores deve ser preservada, principalmente na dimensão psicológica, sendo premente ações de promoção da saúde para reduzir as implicações do atual contexto no bem-estar desses profissionais. ${ }^{14}$ Nesse âmbito, é recomendável o equilíbrio entre trabalho e vida pessoal, praticar exercícios físicos, promover momentos de lazer, como ler e assistir a filmes, manter alimentação saudável, bem como participar de atividades grupais de ajuda mútua, ${ }^{16}$ mesmo que de modo virtual, que são ações que se alinham às estratégias propostas pela Política Nacional de Promoção da Saúde (PNPS). ${ }^{19}$

Na PNPS, é abordado sobre as condições de trabalho, meio ambiente, moradia, lazer, educação, cultura e acesso a bens e serviços essenciais. ${ }^{21}$ Mas, para obter essas condições e atingir um estado de completo bem-estar envolvendo as dimensões do físico, mental, espiritual e social, os docentes precisam ter conhecimento e autonomia para modificar favoravelmente o seu ambiente natural, político e social. ${ }^{22}$ 
19 | Souza JB, Heidemann ITSB, BitencourtIII JVOV, Aguiar DCM, Vendruscolo C, Vitalle MSS

Além disso, a promoção da saúde deve ocorrer amplamente, inclusive nos locais de trabalho, lembrando que a casa dos professores se tornou o seu espaço laboral no período pandêmico, sendo necessário contar com o apoio dos familiares para o bom andamento das suas atividades. $^{18}$ Outro fator a destacar é que algumas professoras, no enfrentamento das repercussões da COVID-19, aproximaram-se mais de Deus, em busca de esperança e fé para prosseguir a jornada da vida. A espiritualidade integra uma das dimensões do ser humano, sendo uma maneira de significar a vida, de ter esperança e estar em paz em meio aos desafios. Assim, cabe aos profissionais da saúde considerar as necessidades espirituais dos indivíduos no seu processo saúde-doença como um recurso a ser utilizado na promoção da saúde. ${ }^{23}$

O fato é que escrever sobre horizontes educacionais incertos é algo intangível. A despeito disso, impõe-se a continuidade, pois parar, estagnar, não é possível. O cenário de crise desperta a criação e recriação, o reinventar na direção da construção de uma sociedade justa e igualitária, que visa sempre à liberdade, autonomia e esperança para todos. Embora com nuances de utopia, é importante que se possa acreditar e almejar concepções e soluções avançadas e tomar esse propósito como ideal social e de vida. Mesmo com as desigualdades sociais e educacionais trazidas por um governo com fracos incentivos para com a classe educacional, somados à situação da COVID-19 que paralisou a educação presencial no Brasil, é preciso repensar a educação em tempos de crise e em termos de esperança, ${ }^{24}$ em prol da sociedade e da saúde ocupacional dos professores.

O Círculo de Cultura de maneira virtual mostrou-se como uma tecnologia de cuidado exitosa para enfermeiros e demais profissionais da área da saúde utilizarem, pois oportunizou diálogo e discussão entre as professoras, que puderam compartilhar experiências na vivência da pandemia. No encontro, utilizou-se a música, que é uma linguagem universal e que despertou profundas emoções nas professoras: diversão, redução do estresse, além de reflexão, o que facilitou o vínculo entre mediadora e participantes. ${ }^{25}$ Assim, o Círculo de Cultura Virtual 
Enfrentamento da COVID-19 e as possibilidades para promover a saúde: diálogos... $\mid 20$

demonstrou ser um espaço acolhedor e promotor da saúde para as professoras participantes, que puderam dialogar sobre as suas angústias e medos, germinando aprendizado mútuo e empoderamento para superar os desafios, lançando novas sementes de esperança para um (re)começar na vida pessoal e no trabalho.

Como fator limitante do estudo, considera-se que algumas professoras atuavam em escolas públicas e outras em instituições privadas, com diferentes realidades. Entre as participantes, havia professoras que não tinham paralisado suas aulas, enquanto outras tinham recentemente iniciado o ensino de maneira remota, estando em diferentes processos de adaptação no momento do estudo. No entanto, as diferentes realidades foram relevantes para a troca de experiências e reflexões sobre o ensino não presencial e seus impactos na saúde dos profissionais da educação no Brasil.

\section{Conclusão}

Durante os diálogos no Círculo de Cultura Virtual, as professoras foram provocadas a exercitar sua consciência crítica sobre o lugar social que ocupam ao ter que improvisar estratégias de ensino on-line, culminando com prováveis implicações na sua própria saúde mental. Elas revelaram a vivência do enfrentamento da COVID-19, destacando os desafios do ensino não presencial, como a necessidade de trabalho remoto, concomitante à função de ser mãe, esposa, dona de casa e professora ao mesmo tempo. Essa condição gerou intenso trabalho, estresse, ansiedade, medo, preocupações, insegurança com a possibilidade de desemprego, saudade da escola e dos diálogos com os estudantes.

Em busca do viver saudável, as docentes também puderam refletir sobre as possibilidades de promover saúde no enfrentamento da COVID-19. Elas apontaram a importância do apoio familiar para vencer os desafios, organizar um tempo para cuidar de si, ter esperança por dias melhores e aliviar a ansiedade por meio de leitura de livros, filmes e prática de exercícios físicos. 
21 | Souza JB, Heidemann ITSB, BitencourtIII JVOV, Aguiar DCM, Vendruscolo C, Vitalle MSS

O Círculo de Cultura Virtual mostrou-se como profícuo na promoção da saúde das professoras. As tecnologias digitais de comunicação ampliam possibilidades de encontros e o compartilhamento de experiências, incrementando, sobremaneira, as formas de aprendizagem. Como dispositivo tecnológico de educação e, ao mesmo tempo, de promoção e prevenção, o Círculo de Cultura Virtual pode ser uma ferramenta utilizada pela Enfermagem, pois oportuniza a integração social e a promoção do bem-estar de indivíduos e coletividades em situações de restrição ou condições que inviabilizem o deslocamento físico. Em estratégias metodológicas para a construção de conhecimento científico, essa modalidade também se mostrou positiva e recomenda-se sua utilização em outras pesquisas dessa natureza.

Como contribuições para a área da Enfermagem e saúde, o ambiente virtual apresentouse como um espaço de interação social, de aprendizagem e de saúde do trabalhador na atual conjuntura pandêmica. Revelou-se como uma ferramenta para o estabelecimento de relações fecundas entre aqueles que atuam na produção de saúde e trabalhadores da área da educação, com possibilidade de aplicabilidade para outros públicos que vêm enfrentando modificações no seu processo laboral para se adequar à nova realidade.

Cabe considerar que para promover a saúde dos trabalhadores da educação, é imprescindível que as condições emocionais e a adaptação psicológica sejam asseguradas. Os desafios que se instalam perpassam a saúde ocupacional dos professores, considerando que a pandemia tem gerado angústias e preocupações, além de indagações perante a condução da situação mundial.

\section{Referências}

1. Organização Pan Americana da Saúde (OPAS). Folha informativa COVID-19 - Escritório da OPAS e $\mathrm{da}$ OMS no Brasil [Internet]. 2020 [acesso 2020 jun 05]. Disponível em: https://www.paho.org/bra/index.php?option=com_content\&view=article\&id=6101:covid19\&Itemid=875

2. Ministério da Saúde (BR), Secretaria de Vigilância em Saúde. Doença pelo Novo Coronavirus - COVID 
Enfrentamento da COVID-19 e as possibilidades para promover a saúde: diálogos... $\mid 22$

19 [Internet]. 2020 [acesso 2020 jun 05]. Disponível em: http://portalarquivos2.saude.gov.br/images/pdf/2020/fevereiro/21/2020-02-21-BoletimEpidemiologico03.pdf

3. Chen Y, Liu Q, Guo D. Emerging coronaviruses: genome structure, replication, and pathogenesis. J Med Virol. 2020;92(4 Spec No):418-23. doi: https://dx.doi.org/10.1002/jmv.25681

4. Ribeiro AP, Oliveira GL, Silva LS, Souza ER. Saúde e segurança de profissionais de saúde no atendimento a pacientes no contexto da pandemia de Covid-19: revisão de literatura. Rev Bras Saúde Ocup. 2020;45:e25. doi: https://doi.org/10.1590/2317-6369000013920

5. Almeida IM. Proteção da saúde dos trabalhadores da saúde em tempos de COVID-19 e respostas à pandemia. Rev Bras Saúde Ocup. 2020;45:e17. doi: https://doi.org/10.1590/scielopreprints.140

6. Rafael RMR, Oliveira Neto M, Carvalho MMB, David HMSL, Acioli S, Faria MGA. Epidemiologia, políticas públicas e Covid-19: o que esperar do Brasil? Rev Enferm UERJ. 2020;28:e49570. doi: https://doi.org/10.12957/reuerj.2020.49570

7. Jackson Filho JM, Assunção AA, Algranti E, Garcia EG, Saito CA, Maeno M. A saúde do trabalhador e o enfrentamento da COVID-19. Rev Bras Saúde Ocup. 2020;45;e14. doi: https://doi.org/10.1590/23176369 ed0000120

8. United Nations Children's Fund (UNICEF). Covid-19: are children able to continue learning during school closures? A global analysis of the potential reach of remote learning policies using data from 100 countries [Internet]. New York (NY): UNICEF; 2020 [cited 2020 Nov 12]. Available from: https://www.unicef.org/brazil/media/10006/file/remote-learning-factsheet.pdf

9. Felcher CDO, Ferreira ALA, Folmer V. Da pesquisa-ação à pesquisa participante: discussões a partir de uma investigação desenvolvida no Facebook. Exp Ensino Ciênc [Internet]. 2017 [acesso 2020 set 29];12(7):1-18. Disponível em: http://if.ufmt.br/eenci/artigos/Artigo_ID419/v12_n7_a2017.pdf

10. Freire P. Pedagogia do oprimido. 61ª ed. Rio de Janeiro: Paz e Terra; 2017.

11. Heidemann ITSB, Dalmolin IS, Rumor PCF, Cypriano CC, Costa MFBNA, Durand MK. Reflexões sobre o itinerário de pesquisa de Paulo Freire: contribuições para a saúde. Texto Contexto Enferm. 2017;26(4):e0680017. doi: https://doi.org/10.1590/0104-07072017000680017

12. Dalmolin IS, Faria LM, Perão OF. Dialogando com Freire no círculo de cultura: uma estratégia de promoção da saúde. Rev Enferm UFPE On Line. 2016 [acesso 2020 jun 05];10(1):185-90. Disponível em: https://periodicos.ufpe.br/revistas/revistaenfermagem/article/view/10937

13. Ghaljaie F, Naderifar M, Goli H. Snowball sampling: a purposeful method of sampling in qualitative research. Strides Dev Med Educ [Internet]. 2017 [cited 2020 Sept 30];4(3):e67670. Available from: https://journals.indexcopernicus.com/search/article?articleId=1772834 
14. Pereira HP, Santos FV, Manenti MA. Saúde mental de docentes em tempos de pandemia: os impactos das atividades remotas. Bol Conjunt. 2020;3(9):26-32. doi: 10.5281/zenodo.3986851

15. Rondini CA, Pedro KM, Duarte CS. Pandemia do Covid-19 e o ensino remoto emergencial: mudanças na práxis docente. Interfaces Cient Educ. 2020;10(1):41-57. doi: 10.17564/2316-3828.2020v10n1p41-57

16. Instituto Península. Sentimento e percepção dos professores brasileiros nos diferentes estágios do Coronavírus no Brasil [Internet]. 2020 [acesso 2020 jun 05]. Disponível em: https://www.institutopeninsula.org.br/wp-content/uploads/2020/03/Pulso-Covid-19_-InstitutoPeni\%CC\%81nsula.pdf

17. Santana FAL, Neves IR. Saúde do trabalhador em educação: a gestão da saúde de professores de escolas públicas brasileiras. Saúde Soc. 2017;26(3):786-97. doi: https://doi.org/10.1590/s010412902017167259

18. Cano DS, Moré CLOO. Estratégias de enfrentamento psicológico de médicos oncologistas clínicos. Psicol Teor Pesqui. 2016;32(3):e323211. doi: 10.1590/0102-3772e323211

19. Vieira SL, Silva GTRS, Rosana MO, Amestoy SC. Diálogo e ensino-aprendizagem na formação técnica em saúde. Trab Educ Saúde. 2016;18(Suppl 1). doi: https://doi.org/10.1590/1981-7746-sol00253

20. Centro de Inovação para a Educação Brasileira. CIEB lança estratégias de aprendizagem remota para secretarias de Educação [Internet]. 2020 [acesso 2020 jun 05]. Disponível em: https://cieb.net.br/cieblanca-estrategias-de-aprendizagem-remota-para-secretarias-de-educacao

21. Heidemann ITSB, Cypriano CC, Gastaldo D, Jackson S, Rocha CG, Fagundes E. Estudo comparativo de práticas de promoção da saúde na atenção primária em Florianópolis, Santa Catarina, Brasil e Toronto, Ontário, Canadá. Cad Saúde Pública. 2018;34(4):1-13. doi: https://doi.org/10.1590/0102$311 \times 00214516$

22. Malta DC, Reis AAC, Jaime PC, Morais Neto OL, Silva MMA, Akerman M. O SUS e a Política Nacional de Promoção da Saúde: perspectiva resultados, avanços e desafios em tempo de crise. Ciênc Saúde Colet. 2018;23(6):1799-809. doi: 10.1590/1413-81232018236.04782018

23. Reginato V, Benedetto MAC, Gallian D. Espiritualidade e saúde: uma experiência na graduação em Medicina e Enfermagem. Trab Educ Saúde. 2016;14(1):237-55. doi: 10.1590/1981-7746-sip00100

24. Silva FC, Brandão CR. Alguns imaginários para pensar a educação em tempos de crise e em termos de esperança. Rev Pedagóg [Internet]. 2019 [acesso em 2020 jun 05];21:20-42. Available from: https://bell.unochapeco.edu.br/revistas/index.php/pedagogica/article/view/4637

25. Souza JB, Martins EL, Xirello T, Urio A, Barbosa SSP, Pitilin EB. Interface entre a música e a promoção da saúde da mulher. Rev Bras Promoç Saúde. 2020;33:1-10. doi: https://doi.org/10.5020/18061230.2019.9466 
Enfrentamento da COVID-19 e as possibilidades para promover a saúde: diálogos... | 24

Editora Científica Chefe: Cristiane Cardoso de Paula

Editora Científica: Tânia Solange Bosi de Souza Magnago

\author{
Autor correspondente \\ Denise Consuelo Moser Aguiar \\ E-mail: denise.moser@uffs.edu.br \\ Endereço: Campus Chapecó-SC; Rodovia SC 484 - Km 02, Fronteira Sul, CEP 89815-899 \\ Telefone: (49) 2049-2600
}

\title{
Contribuições de Autoria
}

1 - Jeane Barros Souza

Concepção ou desenho do estudo/pesquisa

2 - Ivonete Teresinha Schülter Buss Heidemann

Concepção ou desenho do estudo/pesquisa

3 - Julia Valeria de Oliveira Vargas Bitencourt

Análise e/ou interpretação dos dados

4 - Denise Consuelo Moser Aguiar

Revisão final com participação crítica e intelectual no manuscrito

\section{5 - Carine Vendruscolo}

Revisão final com participação crítica e intelectual no manuscrito

\section{6 - Maria Sylvia de Souza Vitalle}

Revisão final com participação crítica e intelectual no manuscrito

\section{Como citar este artigo}

Souza JB, Heidemann ITSB, BitencourtIII JVOV, Aguiar DCM, Vendruscolo C, Vitalle MSS. Enfrentamento da COVID-19 e as possibilidades para promover a saúde: diálogos com professores. Rev. Enferm. UFSM. 2021 [Acesso em: Ano Mês Dia]; vol.11 e12: 1-24. DOI:https://doi.org/10.5902/2179769261363 